\title{
Learning attitudes decisive to students' cognitive and knowledge development
}

Jakobsson, A.

Lund Univ., Malmo, Sweden;

This paper appears in: Computers in Education, 2002. Proceedings. International

Conference on

Publication Date: 3- 6 Dec. 2002

On page(s): 1025- 1029 vol.2

ISSN:

Number of Pages: 2 vol.xliii +1580

\begin{abstract}
:
This study gives an account of a teaching situation with 20 student's aged 14-15. The students have worked with a problem focussed on the greenhouse effect, based on a problem solving way of working. They have worked in groups and have had access to ICT, books, articles and a special resource page on the Internet. The purpose has been to account for the ways in which the students' knowledge develops during the problem solving process and what the factors are that influence learning. In order to explain the causes I have constructed five different "learning attitudes". These are: creators of meaning, constructors of knowledge, ethical evaluators, reproducers and maintainers of relationships. When these learning attitudes are related to the students' knowledge development it becomes evident that the creators of meaning, constructors of knowledge and ethical evaluators have a predominantly stronger cognitive and knowledge development than the reproducers and maintainers of relationships.
\end{abstract}

